University of Nebraska - Lincoln

DigitalCommons@University of Nebraska - Lincoln

Faculty Publications in Food Science and Technology

Food Science and Technology Department

2002

Reduction of Moniliformin During Alkaline Cooking of Corn

Graciela Pineda-Valdes

University of Nebraska-Lincoln

Dojin Ryu

University of Nebraska-Lincoln

David S. Jackson

University of Nebraska-Lincoln, djackson1@unl.edu

Lloyd B. Bullerman

University of Nebraska-Lincoln, Ibullerman1@unl.edu

Follow this and additional works at: https://digitalcommons.unl.edu/foodsciefacpub

Part of the Food Science Commons

Pineda-Valdes, Graciela; Ryu, Dojin; Jackson, David S.; and Bullerman, Lloyd B., "Reduction of Moniliformin During Alkaline Cooking of Corn" (2002). Faculty Publications in Food Science and Technology. 97.

https://digitalcommons.unl.edu/foodsciefacpub/97

This Article is brought to you for free and open access by the Food Science and Technology Department at DigitalCommons@University of Nebraska - Lincoln. It has been accepted for inclusion in Faculty Publications in Food Science and Technology by an authorized administrator of DigitalCommons@University of Nebraska - Lincoln. 


\title{
Reduction of Moniliformin During Alkaline Cooking of Corn ${ }^{1}$
}

\author{
Graciela Pineda-Valdes, ${ }^{2}$ Dojin Ryu, ${ }^{2}$ David S. Jackson, ${ }^{2}$ and Lloyd B. Bullerman ${ }^{2.3}$
}

\begin{abstract}
The incidence of moniliformin (MON) producing Fusarium spp. in selected corn (Zea mavs L.) samples from Mexico and the United States and the effects of alkaline cooking and the tortilla manufacturing processes on the reduction of MON were determined. The percentage of infected kernels with Fusarium spp. ranged from 0 to $22 \%$ in eight foodgrade corn samples, including six from Mexico and two from the United States. Complete $(100 \%)$ reduction of MON was observed when a naturally
\end{abstract}

ABSTRACT

Cereal Chem. 79(6):779-782

contaminated corn sample containing $1.4 \mu \mathrm{g}$ of MON/g of corn was used in a pilot-scale alkaline cooking and tortilla manufacturing process. In a companion laboratory-scale study, using a cultured corn sample containing $17.6 \mu \mathrm{g}$ of MON/g of corn, a $71 \%$ reduction of the toxin was observed during the process. Alkaline cooking appeared to be an effective method for reduction of MON in corn.
Fusarium proliferatum and $F$. subglutinans are known to be the main producers of the mycotoxin moniliformin (MON) in corn (Marasas et al 1979; Farber et al 1988; Lew et al 1996). MON is regarded as cytotoxic but not genotoxic, based on animal studies (Norred et al 1992; Knasmuiller et al 1997). Toxicity studies of MON have shown it to be cardiotoxic. Symptoms in animal species include a progressive muscular weakness, lack of muscular coordination, respiratory distress, cyanosis, coma, and death (Cole et al 1973; Kriek et al 1977; Allen et al 1981). Intestinal and kidney hemorrhages in ducklings have also been reported (Vesonder and Wu 1998).

The natural occurrence of moniliformin was reported at $16 \mu \mathrm{g} / \mathrm{g}$ of corn in samples from the Transkei in South Africa (Thiel et al 1982). Surveys done in numerous countries have found that MON contents ranged from 0.015 to $530 \mu \mathrm{g} / \mathrm{g}$ of corn in cereal grains and finished food products (Sharman et al 1991; Lew et al 1993, 1996; Logrieco 1993; Adler et al 1995; Golinski et al 1997; MAFF-UK 1998). In the United States, $2.92 \mu \mathrm{g}$ of MON/g of corn was reported from corn screenings associated with a field outbreak of leukoencephalomalacia in horses in Pennsylvania (Thiel et al 1986). MON contents of up to $0.87 \mu \mathrm{g} / \mathrm{g}$ of corn were also found in corn and corn-based retail products destined for human consumption (Sharman et al 1991; Gutema et al 2000). Currently, there are no Food and Drug Administration guidelines for MON in food in the United States.

The traditional method of processing corn into tortillas (nixtamalization) was developed by Latin American Indians many centuries ago (Cravioto et al 1952). In this process, corn is cooked in boiling or near-boiling lime solution for a relatively short time and steeped overnight. The cooked steeped corn (nixtamal) is washed to remove excess alkali and loose pericarp tissue. The nixtamal is then ground into masa (corn flour) and flattened into thin disks that are baked on a hot surface (Bedolla and Rooney 1982).

The nixtamalization process has been reported to reduce or eliminate the presence of mycotoxins in corn including aflatoxin, fumonisin, deoxynivalenol, and zearalenone (Price and Jorgensen 1985; Abbas et al 1988; Sydenham et al 1995; Dombrink-Kurtzman et al

\footnotetext{
' Published as Paper No. 12919 Journal Series. Agricultural Research Division, Lincoln, NE 68583. Research was conducted under Project 16-056. This material is based upon work supported by Cooperative State Research Education and Extension Service, U.S. Department of Agricuiture under Agreement No. 9702551, and was also supported in part by a research grant from the Anderson Research Fund of the NC-213 Regional Research Project.

${ }^{2}$ Department of Food Science and Technology, University of Nebraska, Lincoln, NE 68583-0919.

${ }_{3}^{3}$ Corresponding author. E-mail: Jbullerman1@unl.edu. Phone: 402-472-2801. Fax: 402-472-1693.
}

Publication no. C-2002-1001-07R.

(C) 2002 American Association of Cereal Chemists, Inc.
2000). To date, there are no reports of the effects of processing corn under alkaline conditions on the reduction of MON, though we have shown that MON was reduced when heated at high temperatures under alkaline conditions in aqueous solutions (Pineda-Valdes and Bullerman 2000). The experiments described here were designed to determine the incidence of MON-producing fungi in eight selected corn samples and to investigate the effects of the nixtamalization process and tortilla manufacture on the reduction of MON in corn.

\section{MATERIALS AND METHODS}

\section{Corn Samples}

Corn samples used for analysis of MON and for making tortillas in the pilot plant, were obtained from the Cereal Technology Laboratory, University of Nebraska-Lincoln. A total of eight food grade corn samples designated M1-M8 were available. Samples M1-M6 were white corn samples from Mexico, whereas M7 and M8 were yellow corn samples from the United States, but which had been exported to Mexico. The bulk corn samples were cleaned at a commercial corn cleaning facility (Flatwater Milling Inc., Hastings, $\mathrm{NE}$ ). Clean corn was used to determine the percent of kernels infected with total mold and Fusarium. Bulk corn, clean corn, and corn screenings were collected and analyzed for MON content. The samples were ground to a fine meal (except the portions used to determine internal infection) using a grinding/subsampling mill (model 2A, Romer Labs, Union, MO) and frozen until analyzed for MON.

\section{Determination of Incidence of Molds}

Dichloran $18 \%$ glycerol agar (DG18) was used to determine total mold infection (Hocking and Pitt 1980). Czapek's iprodione agar (CZID) was prepared as described by Abildgren et al (1987) and used for the selective determination and isolation of Fusarium species. CZID is a selective medium for Fusarium species and allows the formation of large and easily recognizable colonies. Fifty kernels of corn from each sample were analyzed by the direct plating technique for internal mold infection. Samples were surface sanitized by soaking in full strength household bleach $(5.25 \% \mathrm{NaOCl})$ for $1 \mathrm{~min}$ and rinsed three times with sterile distilled water. The kernels were dried on sterile paper towels and aseptically placed on the surface of prepoured DG18 and CZID agar in petri dishes. All the plates were incubated at $25^{\circ} \mathrm{C}$ for $10-14$ days. The Fusarium species that grew from inside the kernels on CZID were isolated by the single spore technique using water agar (1.8\% agar) as described by Nelson et al (1983). Single spores that germinated on the water agar were transferred to carnation leaf agar (CLA) (Fisher et al 1982) plates and incubated under natural lighting for 14 days at room temperature. The Fusarium species were identified by spore morphology and culture characteristics (Nelson et al 1983). 
Pilot-Plant Scale Nixtamalization

and Tortilla Manufacturing Processes

Water $(80 \mathrm{~kg}$ ) was pumped into a near-commercial size pilot-scale, gas-fired cooking tank (model OCT002-01, Lawrence Equipment, So El Monte, CA). Food grade lime $\left[\mathrm{Ca}(\mathrm{OH})_{2}\right]$ was added to the cooking tank ( $1 \%$, corn basis) and mixed until dispersed. The lime solution was heated to $88^{\circ} \mathrm{C}$ then $20 \mathrm{~kg}$ of corn was added to the tank. Additional heating with gentle agitation was needed to compensate for the temperature drop resulting from the addition of the corn. The corn was cooked for $20 \mathrm{~min}$ once the temperature of the corn-lime solution reached $88^{\circ} \mathrm{C}$. At the end of heating process, the tank was uncovered and the corn was steeped for $16 \mathrm{hr}$. The steeped corn (nixtamal) was then rinsed twice with $50 \mathrm{~kg}$ of water. Water was poured from a measured cylinder into the cooking tank and the nixtamal was vigorously stirred. After the wash water was drained, masa was prepared by grinding the clean nixtamal in a commercial-scale stone grinder (model OCG2000-01, Lawrence Equipment). Masa was sheeted and cut into tortillas in an automated tortilla rolling/sheeting machine (model OFD1002-02, Lawrence Equipment). The tortillas were then baked in a gas-fired automated tortilla baking oven, preheated to $\approx 365^{\circ} \mathrm{C}$. The tortillas were baked for $\approx 3$ min and collected at the end of a continuous cooling conveyer (model OCC1208-03, Lawrence Equipment). Samples of corn and water were collected after each step. All corn, nixtamal, masa, and tortilla samples were dried overnight at room temperature, ground, and frozen until MON analysis.

\section{Laboratory-Scale Nixtamalization} and Tortilla Manufacturing Processes

A culture of Fusarium fujikuroi M-1214 (Fusarium Research Center, Pennsylvania State University) was grown on carnation leaf agar plates for 14 days at room temperature. Spores were harvested with $0.05 \%$ Tween 80 solution and used to inoculate $500 \mathrm{~g}$ of yellow dent corn in 1-gallon glass jars. The moisture content of the corn was adjusted to $\approx 26 \%$ (dry wt basis) by adding distilled water containing $10 \mathrm{~mL}$ of the spore suspension. The corn was incubated in a dark chamber at $25^{\circ} \mathrm{C}$ for four days. Jars were agitated at least twice a day to allow even distribution of the spores and hyphal growth and to prevent clumping. After four days of incubation, the corn was washed three times with distilled water, one time with $0.01 \%$ Tween 80 , and two more times with distilled water to remove excess surface mold hyphae. The corn was then washed as previously described, dried on paper towels, and further dried at $50^{\circ} \mathrm{C}$ overnight. The corn was then ground and analyzed by HPLC for MON content as described below.

For the laboratory-scale nixtamalization and tortilla-making procedures, the conditions used at the pilot-plant level were duplicated. Briefly, $4 \mathrm{~g}$ of food-grade lime were dissolved in 1,600 $\mathrm{mL}$ of cold water, and heated to $88^{\circ} \mathrm{C}$ in a Kitchen Kettle multi-cooker/steamer (National Presto Industries, Eau Claire, WI). Cultured corn (400 g) was cooked in the lime solution for $20 \mathrm{~min}$. The mixture was then transferred to a $1 \mathrm{~L}$ beaker and steeped for $16 \mathrm{hr}$ with the beaker inside a polyfoam container to allow a slower cooling rate and simulate pilot-plant conditions. The corn was then rinsed twice with $500 \mathrm{~mL}$ of water, and masa dough was made using a grinding/ subsampling mill (model 2A, Romer Labs). Tortillas of $13 \mathrm{~cm}$ diameter and $2 \mathrm{~mm}$ thickness were made with a tortilla press, and cooked for $3 \mathrm{~min}$ on each side at $\approx 250^{\circ} \mathrm{C}$. Samples of corn and water were taken after each step. All samples were dried overnight at room temperature and frozen until analyzed for remaining MON.

\section{Mycotoxin Standards}

Purified MON was purchased from Sigma Chemical Co. (St. Louis, MO). Working standard solutions were prepared in $0.05 \mathrm{M}$ sodium dihydrogen phosphate monohydrate $(\mathrm{pH} 5)$ to concentrations up to $200 \mu \mathrm{g} / \mathrm{mL}$. All reagents were of analytical grade, and solvents used for high performance liquid chromatography were of HPLC grade.

\section{Analysis of MON in Corn, Masa, and Tortillas}

MON content in corn samples was determined as described by Munimbazi and Bullerman (1998). A 10-g sample was extracted twice with $50 \mathrm{~mL}$ of $1.0 \%$ tetrabutyl ammonium hydrogen sulfate in water for $30 \mathrm{~min}$ using a wrist-action shaker (Burrel, Pittsburgh, PA). The extracts were centrifuged $(10 \mathrm{~min})$ and filtered through Whatman No. 4 filter paper. To improve the recovery, the MON in the initial masa and samples from each step in the process was extracted by the method developed by Munimbazi and Bullerman (2001). Briefly, 10-g of ground sample was extracted with three $100-\mathrm{mL}$ portions of water heated each time in the microwave oven ( $1,000 \mathrm{~W}$ for $60 \mathrm{sec}$ at $100 \%$ power). The combined extracts were then centrifuged for $10 \mathrm{~min}$ at $5,000 \times g$ and filtered through Whatman No. 4 filter paper. For corn samples, masa and samples from each step, $25 \mathrm{~mL}$ of the filtered extract was partitioned two times with $25 \mathrm{~mL}$ of dichloromethane. The two dichloromethane

TABLE II

Concentration of Moniliformin $(\mu \mathrm{g} / \mathrm{g})$ Remaining

After Making Tortillas from Naturally Contaminated Corn (pilot-plant scale) or Cultured Corn (laboratory-scale)

\begin{tabular}{lcc}
\hline Process Step & Pilot Plant & Laboratory \\
\hline Raw corn (clean) & $1.42 \pm 0.15 \mathrm{a}^{\mathrm{a}}$ & $17.64 \pm 2.16 \mathrm{a}$ \\
Cooked corn & $0.04 \pm 0.01 \mathrm{~b}$ & $8.06 \pm 1.07 \mathrm{~b}$ \\
Cooking water & nd & nd \\
Steeped corn & nd & $6.28 \pm 0.66 \mathrm{c}$ \\
Steep water & nd & nd \\
Corn after rinse 1 & nd & $5.16 \pm 0.45 \mathrm{~d}$ \\
Rinse water 1 & nd & nd \\
Corn after rinse 2 & nd & $5.39 \pm 0.71 \mathrm{~d}$ \\
Rinse water 2 & nd & nd \\
Masa & nd & $5.19 \pm 0.28 \mathrm{~d}$ \\
Tortillas & nd & $5.35 \pm 0.43 \mathrm{~d}$ \\
\hline
\end{tabular}

a Values in the same column with different letters are significantly different $(\alpha=$ 0.05 ).

${ }^{\mathrm{b}}$ Not detected.

TABLE I

Internal Mold Infection Rate (\%) and Occurrence of Moniliformin in Food-Grade Corn Samples ${ }^{\mathrm{a}}$

\begin{tabular}{|c|c|c|c|c|c|c|c|c|}
\hline \multirow[b]{2}{*}{ Sample } & \multirow{2}{*}{$\begin{array}{c}\text { Total Mold } \\
\text { (DG18) }\end{array}$} & \multicolumn{4}{|c|}{ Fusarium } & \multicolumn{3}{|c|}{ Moniliformin $(\mu \mathrm{g} / \mathrm{g})^{\mathrm{b}}$} \\
\hline & & (CZID) & moniliforme & proliferatum & subglutinans & Bulk & Clean & Screenings \\
\hline M1 & 20 & 8 & 4 & 4 & nd & nd & nd & $0.12 \pm 0.00$ \\
\hline M2 & 8 & 8 & 2 & 6 & nd & nd & nd & $0.15 \pm 0.01$ \\
\hline M3 & $\mathrm{nd}^{\mathrm{c}}$ & nd & nd & nd & nd & $0.05 \pm 0.00$ & nd & $0.10 \pm 0.01$ \\
\hline M4 & 80 & 50 & 38 & 12 & nd & nd & nd & $0.07 \pm 0.01$ \\
\hline M5 & 10 & 6 & 6 & nd & nd & $0.09 \pm 0.01$ & $0.01 \pm 0.00$ & $0.38 \pm 0.10$ \\
\hline M6 & 40 & 40 & 14 & 22 & 4 & $0.08 \pm 0.00$ & $0.12 \pm 0.01$ & $0.91 \pm 0.01$ \\
\hline M7 & 26 & 10 & 4 & 4 & 2 & $0.85 \pm 0.10$ & $0.66 \pm 0.06$ & $1.64 \pm 0.01$ \\
\hline M8 & 52 & 16 & 4 & 8 & 4 & $1.50 \pm 0.10$ & $1.42 \pm 0.15$ & $1.85 \pm 0.16$ \\
\hline
\end{tabular}

a Percent of infection in 50 corn kernels.

b Each value represents average of three replicates \pm one standard deviation of the mean.

c Not detected. 
extracts were combined and evaporated to $5-10 \mathrm{~mL}$ at $50^{\circ} \mathrm{C}$ in a water bath under a stream of air. The reduced volume of dichloromethane extract was transferred into a small vial and evaporated to dryness.

Solid phase extraction columns (100 mg, SAX, Supelco, Inc., Bellefonte, PA) were conditioned by eluting $1 \mathrm{~mL}$ of methanol followed by $1 \mathrm{~mL}$ of $0.1 \mathrm{M} \mathrm{o}$-phosphoric acid. The evaporated extract was redissolved in $1 \mathrm{~mL}$ of water and loaded onto the SAX column. The column was washed with $1 \mathrm{~mL}$ of 50:50 methanol-to-water followed by $1 \mathrm{~mL}$ of water. The rinses were discarded and air was forced through the columns to expel all rinse solutions. MON was then eluted with $1 \mathrm{~mL}$ of $0.05 \mathrm{M}$ sodium dihydrogen phosphate monohydrate ( $\mathrm{pH} 5.0)$.

A $20-\mu \mathrm{L}$ aliquot of the final extract was injected into an HPLC system which consisted of a HPLC pump (model 510, Waters Corp., Milford, MA), connected with an injector (EC6W, Valco Instruments Co., Houston, TX), a reverse-phase column (Nova-Pak $\mathrm{C}_{18}$ $150 \times 4.6 \mathrm{~mm}$, Waters) and a model 486 tunable absorbance detector set at $229 \mathrm{~nm}$ with 0.003 AUFS (Waters), controlled by Waters Millenium computer software (v. 2.15, Waters). MON was eluted using isocratic conditions with a mobile phase of 8:92 acetonitrile-to-ion pair solution $(10 \mathrm{~mL}$ of ion-pair modifiers in $990 \mathrm{~mL}$ water, $\mathrm{pH} 6.5$ ) at a flow rate of $1 \mathrm{~mL} / \mathrm{min}$. The ion pair modifiers were prepared by mixing $50 \mathrm{~mL}$ of $40 \%$ tetrabutyl ammonium hydrogen sulfate in $100 \mathrm{~mL}$ of $1.1 \mathrm{M}$ potassium dihydrogen phosphate.

Data of MON content obtained from HPLC were analyzed using analysis of variance (SAS Institute, Cary, NC). Least square means procedures were used to separate means when differences were statistically significant $(P \leq 0.05)$. The entire experiment was replicated three times and all determinations were done in duplicate.

\section{RESULTS AND DISCUSSION}

\section{Kernel Infection and MON Content}

The total mold infection rates (\% kernels infected) in corn samples were $0-80 \%$ when determined on DG18 plates, whereas infection rates of Fusarium spp. were $0-50 \%$ on CZID plates (Table I). Among the Fusarium species identified, $F$. verticillioides (formerly known as $F$. moniliforme) and $F$. proliferatum were more common contaminants than $F$, subglutinans in the corn. Previous reports also indicate these two Fusarium species are common pathogens and endophytes in corn around the world (Chu and $\mathrm{Li}$ 1994; Miller 1995; Marin et al 1996; Kosiak et al 1997). Although F. verticillioides was more common in some samples tested in this study, this species is not known to produce MON. In addition, the incidence of Fusarium spp. was not directly correlated with the MON content of a sample.

The eight samples each of bulk corn, clean corn, and corn screenings were analyzed for MON (Table I). Corn screenings showed the highest concentrations for MON, followed by bulk corn, and clean corn with concentrations of $0.1-1.85,0-1.50$, and $0-1.42 \mu \mathrm{g} / \mathrm{g}$, respectively. These results show that the concentration of MON in corn might be reduced to some extent by cleaning, and that the toxin might be more concentrated in certain fractions such as screenings. Other mycotoxins, including deoxynivalenol and zearalenone, have been reduced by washing with water (Trenholm et al 1992). In addition, mycotoxins tend to be in certain parts of the kernel, which results in varying concentrations in different fractions from processes such as milling (Katta et al 1997). In general, the MON content of the com in this study was similar to concentrations found in other surveys of food-grade corn in the United States, Canada, and Europe (Scott and Lawrence 1987; Lew et al 1993; MAFF-UK 1998; Gutema et al 2000).

\section{Pilot-Plant and Laboratory-Scale Nixtamalization}

The fate of MON in a tortilla manufacturing process simulating a commercial procedure was studied with a cleaned corn sample
(M8) contaminated with the highest naturally occurring concentration of MON $(1.4 \mu \mathrm{g} / \mathrm{g})$ found in this study. Tortillas were prepared using pilot-plant equipment and the results are shown in Table II. The concentration of MON was reduced by $97 \%$ during alkaline cooking of corn from the raw material. MON was not detected in any steps after alkaline-cooking, including the rinsing water. Because of the low initial concentration of MON, either complete loss of the toxin occurred during alkaline cooking or there was a partial loss combined with dilution below detectable levels during the process.

A parallel experiment performed in laboratory scale using cultured corn with an initial concentration of $\mathrm{MON}$ at $17.6 \mu \mathrm{g} / \mathrm{g}$ resulted in a $71 \%$ reduction of MON from the initial concentration in the corn to the final product (Table II). The greatest reduction of MON $(54 \%)$ resulted from the alkaline cooking step. Statistical analysis showed a significant difference $(P \leq 0.05)$ in the concentration of MON between cooked corn (samples taken immediately after cooking) and steeped corn (samples taken after $16 \mathrm{hr}$ of steeping). An additional 10\% reduction of MON occurred during the steeping step following alkaline cooking. Though MON was not detected in the rinse water, toxin content in first-rinse corn was significantly $(P<0.05)$ reduced compared to that in steeped corn. No significant difference was found in MON contents among the samples of rinsed corn, masa, and tortillas. As shown in Table II, no MON was detected in any water sample analyzed, probably because the MON was too diluted to be detected with the method used.

In general, MON was reduced significantly by the nixtamalization process probably due to both heat and alkaline $\mathrm{pH}$. These results agreed with the previous report that MON was not stable when heated in an aqueous solution at $150^{\circ} \mathrm{C}$ and $\mathrm{pH} 10$ (PinedaValdes and Bullerman 2000). The nixtamalization procedure has also been effective for reduction of other mycotoxins. deArriola et al (1988) found nixtamalization to be effective in reducing aflatoxin in corn ( $\approx 89 \%$ reduction). Significant reductions of zearalenone (59$100 \%)$ and deoxynivalenol (72-82\%) were also previously reported (Abbas et al 1988). This study has shown that the nixtamalization process is also an effective method for removing MON from corn.

\section{LITERATURE CITED}

Abbas, H. K., Mirocha, C. J., Rosiles, R., and Carvajal, M. 1988. Decomposition of zearalenone and deoxynivalenol in the process of making tortillas from corn. Cereal Chem. 65:15-19.

Abildgren, M. P., Lund, F., Thrane, U., and Elmholt, S. 1987. CzapekDox agar containing iprodione and dichloran as a selective medium for the isolation of Fusarium species. Lett. Appl. Microbiol. 5:83-86.

Allen, N. K., Burmeister, H. R., Weaver, G. A., and Mirocha, C. J. 1981. Toxicity of dietary and intravenously administered moniliformin to broiler chickens. Poult. Sci. 60:1415-1417.

de Arriola, M. C., de Porres, E., de Cabrera, S., de Zepeda. M., and Rolz, C. 1988. Aflatoxin fate during alkaline cooking of com for tortilla preparation. J. Agric. Food Chem. 36:530-533.

Bedolla, S., and Rooney, L. W. 1982. Cooking maize for masa production. Cereal Foods World 27:219-221.

Chu, F. S., and Li, G. Y. 1994. Simultaneous occurrence of Fumonisin B and other mycotoxins in moldy corn collected from the People's Republic of China in regions with high incidences of esophageal cancer. Appl. Environ. Microbiol. 60:847-852.

Cole, R. J., Kirsey, J. W., Cutler, H. G., Doupnik, B. L., and Peckham. J. C. 1973. Toxin from Fusarium moniliforme: Effects on plant and animals. Science 179:1324-1324.

Cravioto, R. O., Massieu, G. H., Cravioto, O. Y., and Figueroa, F. M. 1952. Effect of untreated corn and Mexican tortilla upon growth of rats fed on a niacin-tryptophan deficient diet. J. Nutr. 48:453-459.

Dombrink-Kurtzman, M. A., and Dvorak, T. J., Barron, M. E., and Rooney, L. W. 2000. Effect of nixtamalization (alkaline cooking) on fumonisin-contaminated corn for production of masa and tortillas. J. Agric. Food Chem. 48:5781-5786.

Farber, J. M., Sanders, G. W., Lawrence, G. A., and Scott, P. M. 1988. Production of moniliformin by Canadian isolates of Fusarium. Mycopathologia 101:187-190.

Fisher, N. L., Burgess, L. W., Toussoun. T. A., and Nelson, P. E. 1982. 
Carnation leaves as a substrate and for preserving cultures of Fusarium species. Phytopathology 72:151-153.

Gutema, T., Munimbazi, C., and Bullerman, L. B. 2000. Occurrence of fumonisins and moniliformin in corn and corn-based food products of U.S. origin. J. Food Prot. 63:1732-1737.

Hocking, A. D., and Pitt, J. I. 1980. Dichloran-glycerol medium for enumeration of xerophilic fungi from low-moisture foods. Appl. Environ. Microbiol. 39:488-492.

Katta, S. K., Cagampang, A. E., Jackson, L. S., and Bullerman, L. B. 1997. Distribution of Fusarium molds and fumonisins in dry-milled corn fractions. Cereal Chem. 74:858-863.

Knasmüller, S., Bresgen, N., Kassie, F. Sundermann, V. M., Gelderblom, W., Zöhrer, E., and Eckl, P. M. 1997. Genotoxic effects of three Fusarium mycotoxins, fumonisin $\mathrm{B}_{1}$, moniliformin, and vomitoxin in bacteria and in primary cultures of rat hepatocytes. Mut. Res. 391:39-48.

Kosiak, B., Torp, M., and Thrane, U. 1997. The occurrence of Fusarium spp. in Norwegian grain-A survey. Cereal Res. Comm. 25:595-596.

Kriek, N. P. J., Marasas, W. F. O., Steyn, P. S., van Rensburg, S. J., and Steyn, M. 1977. Toxicity of a moniliformin producing strain of Fusarium moniliforme var subglutinans isolated from maize. Food Cosmet. Toxicol. 15:579-587.

Lew, H., Chelkowski, J., Wakulinski, W., and Edinger, W. 1993. Moniliformin in wheat and triticale grain. Mycotoxin Res. 9:66-71.

Lew, H., Chelkowski, J., Pronczuk, P., and Edinger, W. 1996. Occurrence of the mycotoxin moniliformin in maize (Zea mays L.) ears infected by Fusarium subglutinans (Wollenw. \& Reinking). Food Addit. Contam. 13:321-324.

MAFF-UK. 1998. Surveillance of moniliformin in maize, maize products and the effects of milling. Food Surveillance Paper. No. 164 (HMSO). Ministry of Agriculture, Fisheries and Food: London.

Marasas, W. F. O., Kriek, N. P. J., Wiggins, V. M., Steyn, P. S., Towers, D. K., and Hastie, T. J. 1979. Incidence, geographic distribution and toxigenicity of Fusarium species in South African corn. Phytopathology 69:1181-1185.

Marin, S., Sanchis, V., Teixido, A., Saenz, R., Ramos, A. J., Vinas, I., and Magan, N. 1996. Water and temperature relations and microconidial germination of Fusarium moniliforme and Fusarium proliferatum from maize. Can. J. Microbiol. 42:1045-1050.

Miller, J. D. 1995. Review. Fungi and mycotoxins in grain: Implications for stored product research. J. Stored Prod. Res. 31:1-16.

Munimbazi. C., and Bullerman, L. B. 1998. High-performance liquid chromatographic method for the determination of moniliformin in corn. J. AOAC Int. 81:999-1004.

Munimbazi, C., and Bullerman, L. B. 2001. Chromatographic method for the determination of the mycotoxin moniliformin in com. Pages 131145 in: Methods in Molecular Biology, Vol. 157: Mycotoxin Protocols. M. W. Trucksess and A. E. Pohland, eds. Humana Press: Totowa, NJ.

Nelson, P. E., Toussoun, T. A., and Marasas. W. F. O. 1983. Fusarium species: An illustrated manual for identification. The Pennsylvania State University Press: University Park, PA.

Norred, W. P., Plattner, R. D., Vesonder, R. F., Bacon, C. W., and Voss, K. A. 1992. Effects of selected secondary metabolites of Fusarium moniliforme on unscheduled synthesis of DNA by rat primary hepatocytes. Food Chem. Toxicol. 30:233-237.

Pineda-Valdes, G., and Bullerman, L. B. 2000. Thermal stability of moniliformin at varying temperature, $\mathrm{pH}$ and time in an aqueous environment. J. Food Prot. 63:1598-1601.

Price, R. L., and Jorgensen, K. V. 1985. Effects of processing on alfatoxin levels and on mutagenic potential of tortillas made from naturally contaminated corn. J. Food Sci. 50:347-349.

Rice, L. G., Ross, P. F, Dejong. J., Plattner, R. D., and Coat, J. R. 1995. Evaluation of a liquid chromatographic method for the determination of fumonisins in corn, poultry feeds, and Fusarium culture material J. Assoc. Off. Anal Chem. 78:1002-1009.

Scott, P. M., and Lawrence, G. A. 1987. Determination and stability of the Fusarium mycotoxin moniliformin in cereal grains. J. Assoc. Anal Chem. 70:850-853.

Sharman, M., Gilbert, J., and Chelkowski, J. 1991. A survey on the occurrence of the mycotoxin moniliformin in cereal samples from sources worldwide. Food. Addit. Contam. 8:459-466.

Sydenham, E. W., Stockenström. S., Thiel, P. G., Shephard, G. S., Koch, K. R., and Marasas, W. F. O. 1995. Potential of alkaline hydrolysis for the removal of fumonisins from contaminated corn. J. Agric. Food Chem. 43:1198-1201.

Thiel, P. G., Meyer, C. J., and Marasas, W. F. O. 1982. Natural occurrence of moniliformin together with deoxynivalenol and zearalenone in Transkeian corn. J. Agric. Food Chem. 30:308-312.

Trenholm, H. L., Charmley, L. L.. Prelusky, D. B., and Warner, R. M. 1992. Washing procedures using water or sodium carbonate solutions for the decontamination of three cereals contaminated with deoxynivalenol and zearalenone. J. Agric. Food Chem. 40:2147-2151.

Vesonder, R. F, and Wu, W. 1998. Correlation of moniliformin, but not fumonisin $\mathrm{B}_{1}$ levels, in culture materials of Fusarium isolates to acute death in ducklings. Poult. Sci. 77:67-72.

[Received March 19, 2002. Accepted July 2, 2002.] 